University of Nebraska - Lincoln

DigitalCommons@University of Nebraska - Lincoln

1979

\title{
Age Determination of Mallards
}

\author{
Gary L. Krapu \\ USGS Northern Prairie Wildlife Research Center, gkrapu@usgs.gov \\ Douglas H. Johnson \\ USGS Northern Prairie Wildlife Research Center, Douglas_H_Johnson@usgs.gov \\ Charles W. Dane \\ USGS Northern Prairie Wildlife Research Center
}

Follow this and additional works at: https://digitalcommons.unl.edu/usgsnpwrc

Part of the Other International and Area Studies Commons

Krapu, Gary L.; Johnson, Douglas H.; and Dane, Charles W., "Age Determination of Mallards" (1979). USGS Northern Prairie Wildlife Research Center. 211.

https://digitalcommons.unl.edu/usgsnpwrc/211

This Article is brought to you for free and open access by the US Geological Survey at DigitalCommons@University of Nebraska - Lincoln. It has been accepted for inclusion in USGS Northern Prairie Wildlife Research Center by an authorized administrator of DigitalCommons@University of Nebraska - Lincoln. 


\section{AGE DETERMINATION OF MALLARDS}

GARY L. KRAPU, U.S. Fish and Wildlife Service, Northern Prairie Wildlife Research Center, Jamestown, ND 58401 DOUGLAS H. JOHNSON, U.S. Fish and Wildlife Service, Northern Prairie Wildlife Research Center, Jamestown, ND 58401 CHARLES W. DANE, U.S. Fish and Wildlife Service, Northern Prairie Wildlife Research Center, Jamestown, ND $58401^{1}$

Abstract: A technique for distinguishing adult from yearling wild mallards (Anas platyrhynchos), from late winter through the nesting season, was developed by applying discriminant analysis procedures to selected wing feather characters of 126 yearlings and 76 adults (2-year-olds) hand-reared from wild eggs during 1974, 1975, and 1977. Average values for feather characters generally increased as the birds advanced from yearlings to adults. Black-white surface area of greater secondary covert 2 was the single most reliable aging character identified during the study. The error rate was lowest in females $(3 \%)$ when discriminant functions were used with measurements of primary 1 weight and black-white area cf greater secondary covert 2 and in males $(9 \%)$ when the functions were used with black-white area of greater secondary coverts 1,2 , and 3 . Methodology precludes aging of birds in the field during capture operations.

J. WILDL. MANAGE. 43(2):384-393

Although the mallard has been studied widely, only limited information has been published on age-related aspects of its life cycle, especially age-related productivity. This paucity of information can be attributed, in part, to the lack of a reliable aging technique applicable during the nesting season. Although keys have been developed on the basis of certain wing feather characters to determine age of mallards during the fall and winter (Carney and Geis 1960, Carney 1964), the reliability of these characters during the breeding season is diminished because of feather replacement and wear before and during the nesting season.

The present study was undertaken to develop a technique for reliably separating yearling from older (adult) mallards from late winter to the onset of wing molt in late summer. Several feather measurements were chosen for establishing discriminant functions for each group. Wing feathers were selected on the basis of observed patterns of variation in feather characters, with knowledge of age-related feather variation based on published

\footnotetext{
${ }^{1}$ Present address: Division of Wildlife Research, U.S. Fish and Wildlife Service, Washington, DC 20240.
}

literature, and on the basis of pattern and timing of molt. Variation in primary feather lengths of yearlings and adults was recognized in blue-winged teal, Anas discors (Dane 1968), and redhead, Aythya americana (Dane and Johnson 1975). Wing covert markings were used to age yearlings of certain species, including gadwall, Anas strepera (Oring 1968); common merganser, Mergus merganser (Anderson and Timken 1971); redhead (Smart 1962, Dane and Johnson 1975); and blue-winged teal (Dane 1968).

We thank C. W. Shaiffer, who made most of the measurements; B. A. Hanson for assistance in data collection; T. J. Dwyer for his encouragement and help during development of the study; D. C. McGlauchlin, Manager, Audubon National Wildlife Refuge, for support in obtaining mallard eggs for aging studies; F. B. Lee for supervising the rearing of known-age mallards; and R. J. Greenwood for critically reviewing the manuscript.

\section{METHODS}

Mallards were obtained from wild eggs gathered in central North Dakota during May and June, 1974, 1975, and 1977. Young hatched from about 75 clutches 
Table 1. Years (1976-78) in which measurements were taken on selected wing feathers of known-age mallards during the development of an aging technique.

\begin{tabular}{|c|c|c|c|c|c|c|}
\hline \multirow[b]{2}{*}{ Feather } & \multirow[b]{2}{*}{ Symbol } & \multicolumn{5}{|c|}{ Feather measurements taken } \\
\hline & & Length & Weight & Diameter $^{\mathbf{a}}$ & $\begin{array}{l}\text { Black-white } \\
\text { area }\end{array}$ & Width ${ }^{\mathrm{b}}$ \\
\hline \multicolumn{7}{|l|}{ Primary } \\
\hline $1^{\mathrm{c}}$ & P1 & $76 / 77 / 78$ & $76 / 77 / 78$ & $76 / 77$ & & \\
\hline $5^{\mathrm{d}}$ & P5 & $76 / 77$ & $76 / 77$ & $76 / 77$ & & \\
\hline 9 & P9 & 76 & 76 & 76 & & \\
\hline Primary covert 9 & PC9 & 76 & 76 & 76 & & \\
\hline Alula & A & 76 & 76 & 76 & & \\
\hline \multicolumn{7}{|l|}{$\begin{array}{l}\text { Greater secondary } \\
\text { covert }\end{array}$} \\
\hline 1 (males only) & $\mathrm{C} 1$ & 76 & 76 & & 76 & 76 \\
\hline 2 & $\mathrm{C} 2$ & $76 / 77 / 78$ & $76 / 77 / 78$ & & $76 / 77 / 78$ & $76 / 77$ \\
\hline 3 & C3 & $76 / 77 / 78$ & $76 / 77 / 78$ & & $76 / 77 / 78$ & $76 / 77$ \\
\hline 10 & C10 & 76 & 76 & & 76 & 76 \\
\hline 11 & C11 & 76 & 76 & & 76 & 76 \\
\hline
\end{tabular}

a Horizontal and vertical diameters were measured on each feather shaft.

Maximum width and midwidth were measured on each covert.

c Males only in 1977.

d Females only in 1977.

formed the groups used in aging studies. Captive birds were reared and kept at the Northern Prairie Wildlife Research Center. Selected wing feathers were removed from 202 of the mallards-126 yearlings and 76 adults. Feathers from each bird were labeled and placed in envelopes for later measurement.

On 24 March 1976, 10 wing feathers were pulled for measurement from each of 59 males, and 9 feathers (greater secondary covert 1 excluded) from each of 70 females (Table 1). A maximum of 50 measurements per male and 44 per female were made. On 17 February 1977, 3 feathers were pulled from each of 50 surviving 2-year-olds from the yearling class of 1976. On 15 February 1978, 3 feathers were pulled from 73 yearlings. Feathers pulled in 1977 and 1978 (Table 1) were those best suited for aging as determined from a preliminary analysis of earlier data. Measurements affected by feather damage were excluded from all samples. Primaries were numbered from proximal to distal position on the wing and secondary coverts were numbered from the distal to proximal position. The identification label attached to each feather was covered during measurement and replaced with a coded number to eliminate possible bias resulting from prior knowledge of a bird's age. Feathers were preened into normal shape before measurements were taken.

Feather length $(L)$ was measured from the tip of the quill to tip of vane after the feather was flattened and straightened against a millimeter rule. Feather weight and diameter were measured after feathers were dried for 24 hours at $50 \mathrm{C}$ in a forced air oven, as recommended by Greenberg et al. (1972). Weight (W) was measured to the nearest $0.01 \mathrm{~g}$ on a Mettler balance. Feather diameter was measured to the nearest $0.01 \mathrm{~mm}$ with a dial indicator pocket gauge with flat surface tips. Shaft diameters were measured in the plane of the vane at the superior umbilicus $(H)$ and perpendicular to this plane at the same point $(V)$. Maximum feather width (MAX) and midwidth 


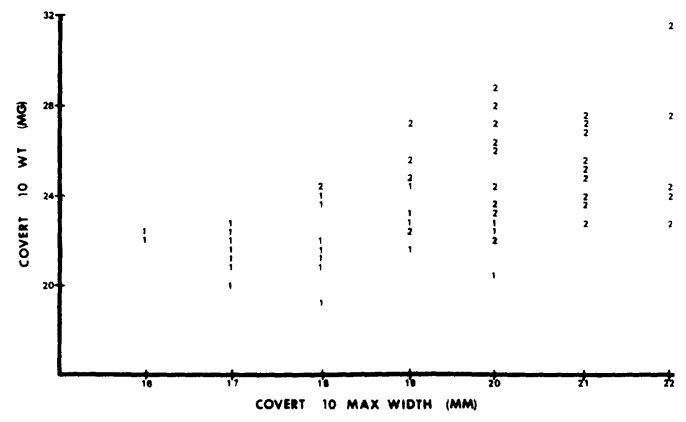

Fig. 1. Bivariate plot of measurements, from female mallards, of greater secondary covert 10 weight and maximum width. Yearlings are plotted with a "1," and 2-year-olds with a "2."

(MID) at the point where the lower edge of the subterminal white area of the feather intersects the shaft, were measured on each greater secondary covert; the latter measurement was excluded for greater secondary coverts that lacked white. Greater secondary coverts were examined for potential feather markings that showed discrete age-related differences in feather coloration. Black and white markings at the distal end of certain coverts were determined to merit further study after initial examination. The size of the black-white area $(B W)$ on each greater secondary covert was measured by superimposing a transparent grid (in $\mathrm{mm}^{2}$ ) over this area.

We used discriminant analysis as the primary statistical method to distinguish yearlings from adults. This technique was used successfully to age female redhead ducks by Dane and Johnson (1975). In discriminant analysis, a linear combination of measurements (a discriminant function or DF) is found that will have a positive value if applied to the measurements of a yearling, and negative if applied to those of an adult. Discriminant analysis allowed several measurements to be used in combination, and accounted for intercorrelations and differing variances among them. We used the discrim- inant analysis and data plotting computer programs of SAS 76 (Barr et al. 1976) on an IBM 360/50.

All measurements for each bird were entered on computer cards for data processing. Initially, we made bivariate plots for pairs of measurements (e.g., Fig. 1). Each point was plotted with a " 1 " if the bird was a yearling and " 2 " if an adult. Such plots performed several useful functions. First, they enabled easy detection of outliers-points that were distant from other values for the same measurements. Outliers were rechecked for errors in coding or mensuration. Second, the plots suggested measurements or combinations of measurements useful for separating the age classes. These measurements received emphasis in further analyses. For example, the combination of C10W and C10MAX had better separation power than either measurement used singly (Fig. 1).

After the points had been plotted and mean values of yearlings and adults had been compared, numerous discriminant analyses were performed. In this preliminary treatment, observations with missing data were excluded from analyses in which those data were employed. For example, a bird whose $\mathrm{P} 1 H$ could not be measured was included in all analyses except those in which $\mathrm{P} 1 H$ was a variate. This method of excluding missing data is not efficient (Lachenbruch 1975), but was adequate for our initial purpose of screening combinations of measurements with potential for distinguishing age classes.

During the course of our analysis, the birds that were measured as yearlings developed into adults. These birds provided valuable information about changes in feather characteristics and also served as a known-age group for testing the preliminary discriminant functions. 
In our final discriminant analyses, we sought functions (DFs) with maximum power to distinguish age classes, but that employed only a few measurements from a few selected feathers. The DFs were developed for various sets of feathers so that other investigators using different feathers could employ the aging technique. Few measurements were used because discriminant functions become increasingly unstable as the number of variables included increases.

Further, missing data were estimated so that all observations could be used. One of 2 methods was employed, depending on the size of the multiple correlation coefficient $\left(R^{2}\right)$ relating the missing measurement to other measurements (Chan and Dunn 1972). If the missing measurement was not well predicted by the others (as suggested by a low $R^{2}$ ), the missing value was replaced by the mean of that measurement available from other ducks of the same sex and age. If the missing measurement was well predicted by the others (high $R^{2}$ ), the estimate from the regression equation was used.

We evaluated the DFs by estimating their error rates-the likelihood of incorrectly classifying adults as yearlings or yearlings as adults. One such estimate is the "apparent error rate," the number of observations used in forming the DF that are erroneously classified by the DF. The apparent error rate tends to be biased low because the observations are the same as those used in calculating the DF and are more likely to be classified correctly than is an independent observation. The bias in the apparent error rate is minor when the number of observations is large relative to the number of variables in a DF. An error rate that overcomes this bias is the estimated error rate $D S$ method of Lachenbruch and Mickey (1968), which does, however, require the assumption that the measurements are distributed normally. We calculated both error rates.

\section{RESULTS}

Average values of selected feather measurements were larger for adults than for yearlings (Table 2). Average length and weight of P1 and P5 increased somewhat with age. Mean length and weight of P9 were based on a small sample, as most measurements were excluded because of feather damage or excessive wear. Greater secondary coverts were only slightly longer in adults than in yearlings. Weight was a more distinctive age-related character, in part reflecting the greater width of coverts from adults. The most profound age-related difference among the chosen feather characters was in the combined black-white surface area (Fig. 2). Among females, for example, combined black-white surface area of $\mathrm{C} 2$ averaged $9.6 \pm 10.2 \mathrm{~mm}^{2}$ (mean \pm SD) among yearlings and 55.8 $\pm 18.5 \mathrm{~mm}^{2}$ among adults (Table 2). Black-white surface area among 6 wild hens known to be adults was $72.2 \pm 21.9$ $\mathrm{mm}^{2}$. The latter group was not restricted to 2-year-olds.

The degree of separation of yearling and adult hens on the basis of combined black-white surface area of C2 is shown in Fig. 3. Overlap between the 2 age groups which are formed by the same individuals as yearlings and adults is small. A significant number (12\%) of yearling females lacked any black or white on C2, but no adults lacked both markings completely. Of the C2 feathers of yearling females, 55\% lacked black and $17 \%$ lacked white, whereas among adult females only $2 \%$ were without black and none was without white.

A preliminary screening of the suitability of feather characters shown in Ta- 
Table 2. Means and standard deviations for selected measurements of feathers of yearling $(Y)$ and adult (A) female and male mallards reared from wild eggs collected in North Dakota.

\begin{tabular}{|c|c|c|c|c|c|}
\hline \multirow{2}{*}{$\begin{array}{c}\text { Sex, } \\
\text { characteristic, } \\
\text { and age group }\end{array}$} & \multicolumn{5}{|c|}{ Feather } \\
\hline & $\mathrm{C} 1$ & $\mathrm{C} 2$ & $\mathrm{C} 3$ & $\mathrm{Cl0}$ & $\mathrm{C} 11$ \\
\hline \multicolumn{6}{|l|}{ Females $^{a}$} \\
\hline \multicolumn{6}{|c|}{ Length (mm) } \\
\hline $\mathrm{Y}$ & & $75.8 \pm 2.4$ & $75.0 \pm 2.5$ & $58.5 \pm 2.1$ & $57.8 \pm 1.8$ \\
\hline A & & $76.1 \pm 2.5$ & $74.9 \pm 2.6$ & $59.2 \pm 2.1$ & $58.1 \pm 2.3$ \\
\hline \multicolumn{6}{|l|}{ Weight (g) } \\
\hline $\mathrm{Y}$ & & $33.2 \pm 2.6$ & $31.6 \pm 2.5$ & $21.8 \pm 1.1$ & $21.5 \pm 1.5$ \\
\hline A & & $35.9 \pm 2.8$ & $34.4 \pm 2.9$ & $24.9 \pm 2.2$ & $24.5 \pm 2.2$ \\
\hline \multicolumn{6}{|c|}{ Midwidth (mm) } \\
\hline $\mathrm{Y}$ & & $12.7 \pm 1.3$ & $14.4 \pm 1.3$ & $16.5 \pm 1.4$ & $16.9 \pm 1.5$ \\
\hline A & & $15.5 \pm 1.3$ & $16.6 \pm 1.3$ & $19.1 \pm 1.1$ & $19.3 \pm 1.2$ \\
\hline \multicolumn{6}{|c|}{ Black-white $\left(\mathrm{mm}^{2}\right)$} \\
\hline $\mathrm{Y}$ & & $9.6 \pm 10.2$ & $28.7 \pm 20.7$ & $84.2 \pm 17.2$ & $72.2 \pm 13.9$ \\
\hline A & & $55.8 \pm 18.5$ & $80.9 \pm 19.7$ & $118.6 \pm 20.0$ & $108.9 \pm 15.4$ \\
\hline \multicolumn{6}{|c|}{ Max-width (mm) } \\
\hline Y & & $16.9 \pm 0.9$ & $16.7 \pm 1.0$ & $18.1 \pm 1.2$ & $18.6 \pm 1.4$ \\
\hline A & & $17.7 \pm 1.1$ & $18.2 \pm 1.2$ & $20.4 \pm 1.0$ & $20.8 \pm 1.1$ \\
\hline \multicolumn{6}{|c|}{ Horizontal diameter (mm) } \\
\hline \multicolumn{6}{|c|}{$\mathrm{Y}$} \\
\hline \multicolumn{6}{|l|}{ A } \\
\hline \multicolumn{6}{|c|}{ Vertical diameter $(\mathrm{mm})$} \\
\hline \multicolumn{6}{|l|}{$\mathrm{Y}$} \\
\hline \multicolumn{6}{|l|}{ A } \\
\hline \multicolumn{6}{|l|}{ Males $^{c}$} \\
\hline \multicolumn{6}{|c|}{ Length (mm) } \\
\hline Y & $74.1 \pm 3.5$ & $76.9 \pm 2.5$ & $74.9 \pm 2.9$ & $57.3 \pm 2.8$ & $56.0 \pm 2.4$ \\
\hline A & $75.1 \pm 3.2$ & $77.6 \pm 2.6$ & $75.6 \pm 2.8$ & $58.5 \pm 2.0$ & $56.5 \pm 2.2$ \\
\hline \multicolumn{6}{|l|}{ Weight (g) } \\
\hline $\mathrm{Y}$ & $29.3 \pm 2.0$ & $34.6 \pm 3.2$ & $32.6 \pm 3.0$ & $21.5 \pm 2.1$ & $20.7 \pm 2.1$ \\
\hline A & $32.7 \pm 3.0$ & $37.3 \pm 2.7$ & $35.5 \pm 2.7$ & $24.9 \pm 1.8$ & $24.0 \pm 1.9$ \\
\hline \multicolumn{6}{|c|}{ Midwidth (mm) } \\
\hline $\mathrm{Y}$ & 一 & $13.5 \pm 1.5$ & $14.1 \pm 1.3$ & $18.2 \pm 2.4$ & $16.6 \pm 1.2$ \\
\hline A & $13.3 \pm 1.6$ & $16.0 \pm 1.1$ & $16.8 \pm 1.2$ & $20.2 \pm 1.8$ & $18.9 \pm 1.6$ \\
\hline \multicolumn{6}{|c|}{ Black-white $\left(\mathrm{mm}^{2}\right)$} \\
\hline $\mathrm{Y}$ & $3.0 \pm 4.4$ & $18.9 \pm 14.7$ & $40.6 \pm 19.0$ & $69.3 \pm 22.2$ & $61.5 \pm 16.3$ \\
\hline A & $25.0 \pm 11.9$ & $60.8 \pm 19.0$ & $77.2 \pm 16.1$ & $97.9 \pm 19.1$ & $83.5 \pm 17.3$ \\
\hline \multicolumn{6}{|c|}{ Max-width (mm) } \\
\hline Y & $17.4 \pm 1.2$ & $18.5 \pm 1.2$ & $16.0 \pm 1.1$ & $19.1 \pm 2.0$ & $18.5 \pm 1.4$ \\
\hline A & $18.3 \pm 1.2$ & $18.7 \pm 1.2$ & $18.4 \pm 1.1$ & $21.6 \pm 1.3$ & $20.9 \pm 1.6$ \\
\hline \multicolumn{6}{|c|}{ Horizontal diameter (mm) } \\
\hline \multicolumn{6}{|c|}{$\mathrm{Y}$} \\
\hline \multicolumn{6}{|l|}{ A } \\
\hline \multicolumn{6}{|c|}{ Vertical diameter (mm) } \\
\hline $\begin{array}{l}\mathrm{Y} \\
\mathrm{A}\end{array}$ & & & & & \\
\hline
\end{tabular}


Table 2. Continued.

\begin{tabular}{|c|c|c|c|c|c|}
\hline \multirow{2}{*}{$\begin{array}{c}\text { Sex, } \\
\text { characteristic, } \\
\text { and age group }\end{array}$} & \multicolumn{5}{|c|}{ Feather } \\
\hline & P1 & P5 & P9 & PC9 & A \\
\hline \multicolumn{6}{|l|}{ Females $^{\mathbf{a}}$} \\
\hline \multicolumn{6}{|l|}{ Length (mm) } \\
\hline $\mathrm{Y}$ & $135.4 \pm 3.1$ & $173.5 \pm 3.9$ & $-^{b}$ & $95.0 \pm 2.4$ & $81.0 \pm 4.2$ \\
\hline A & $137.8 \pm 3.5$ & $177.4 \pm 3.9$ & $208.8 \pm 5.6$ & $98.4 \pm 3.0$ & $80.6 \pm 3.9$ \\
\hline \multicolumn{6}{|l|}{ Weight (g) } \\
\hline $\mathrm{Y}$ & $158.6 \pm 8.9$ & $277.1 \pm 16.3$ & - & $71.6 \pm 4.1$ & $89.4 \pm 9.3$ \\
\hline A & $172.3 \pm 10.0$ & $298.5 \pm 17.0$ & $438.2 \pm 23.6$ & $83.9 \pm 6.1$ & $91.1 \pm 8.8$ \\
\hline \multicolumn{6}{|c|}{ Midwidth (mm) } \\
\hline \multicolumn{6}{|c|}{$\begin{array}{l}\mathrm{Y} \\
\mathrm{A}\end{array}$} \\
\hline A & & & & & \\
\hline \multicolumn{6}{|c|}{ Black-white $\left(\mathrm{mm}^{2}\right)$} \\
\hline \multicolumn{6}{|c|}{$\mathrm{Y}$} \\
\hline \multicolumn{6}{|l|}{ A } \\
\hline \multicolumn{6}{|c|}{ Max-width (mm) } \\
\hline \multicolumn{6}{|c|}{$\mathrm{Y}$} \\
\hline \multicolumn{6}{|l|}{ A } \\
\hline \multicolumn{6}{|c|}{ Horizontal diameter (mm) } \\
\hline $\mathrm{Y}$ & $3.2 \pm 0.2$ & $3.5 \pm 0.1$ & $3.4 \pm 0.1$ & $2.1 \pm 0.1$ & $2.1 \pm 0.2$ \\
\hline A & $3.4 \pm 0.1$ & $3.7 \pm 0.1$ & $3.6 \pm 0.1$ & $2.2 \pm 0.2$ & $2.2 \pm 0.1$ \\
\hline \multicolumn{6}{|c|}{ Vertical diameter (mm) } \\
\hline $\mathrm{Y}$ & $2.8 \pm 0.1$ & $3.4 \pm 0.1$ & $3.6 \pm 0.1$ & $2.1 \pm 0.1$ & $2.2 \pm 0.1$ \\
\hline A & $3.0 \pm 0.1$ & $3.6 \pm 0.1$ & $3.7 \pm 0.1$ & $2.4 \pm 0.1$ & $2.3 \pm 0.1$ \\
\hline \multicolumn{6}{|l|}{ Males $^{c}$} \\
\hline \multicolumn{6}{|c|}{ Length (mm) } \\
\hline $\mathrm{Y}$ & $138.8 \pm 3.3$ & $181.9 \pm 4.4$ & - & $100.2 \pm 3.4$ & $84.5 \pm 2.7$ \\
\hline A & $143.0 \pm 3.8$ & $186.3 \pm 5.5$ & - & $102.7 \pm 3.2$ & $84.8 \pm 3.0$ \\
\hline \multicolumn{6}{|l|}{ Weight (g) } \\
\hline $\mathrm{Y}$ & $170.4 \pm 10.1$ & $310.9 \pm 18.2$ & - & $81.6 \pm 7.0$ & $99.4 \pm 8.4$ \\
\hline A & $186.2 \pm 12.5$ & $333.8 \pm 26.8$ & - & $94.8 \pm 8.5$ & $104.3 \pm 8.0$ \\
\hline \multicolumn{6}{|c|}{ Midwidth (mm) } \\
\hline \multirow{2}{*}{\multicolumn{6}{|c|}{$\begin{array}{l}\mathrm{Y} \\
\mathrm{A}\end{array}$}} \\
\hline & & & & & \\
\hline \multicolumn{6}{|c|}{ Black-white $\left(\mathrm{mm}^{2}\right)$} \\
\hline \multicolumn{6}{|l|}{ Y } \\
\hline A & & & & & \\
\hline \multicolumn{6}{|c|}{ Max-width (mm) } \\
\hline $\mathrm{Y}$ & & & & & \\
\hline A & & & & & \\
\hline Horizontal d & eter (mm) & & & & \\
\hline $\mathrm{Y}$ & $3.3 \pm 0.1$ & $3.6 \pm 0.1$ & $3.5 \pm 0.1$ & $2.1 \pm 0.1$ & $2.2 \pm 0.1$ \\
\hline A & $3.4 \pm 0.2$ & $3.8 \pm 0.1$ & $3.8 \pm 0.1$ & $2.3 \pm 0.1$ & $2.3 \pm 0.1$ \\
\hline Vertical dian & $\mathrm{r}(\mathrm{mm})$ & & & & \\
\hline $\mathrm{Y}$ & $2.9 \pm 0.2$ & $3.6 \pm 0.1$ & $3.8 \pm 0.1$ & $2.3 \pm 0.2$ & $2.3 \pm 0.1$ \\
\hline A & $3.2 \pm 0.2$ & $3.7 \pm 0.2$ & $3.9 \pm 0.1$ & $2.5 \pm 0.1$ & $2.4 \pm 0.1$ \\
\hline
\end{tabular}

ample size is 66 yearling females (all measurements were taken on selected feathers of 30 birds; P1, C2, and C3 measurements were taken on an additional 36 yearling females) and 69 adult females (the latter sample is for P5, C2, and C3 measurements only); 40 adult females form the sample for the remaining measurements. Certain measurements were omitted because of feather wear or damage so sample size used to calculate means of individual feathers is slightly less than total sample size.

b Omitted because mean is based on sample of less than 10 measurements.

c Sample size is 60 yearling males ( $\mathrm{P} 1, \mathrm{C2}$, and C3 measurements only); 23 yearling males form the sample for the remaining measurements. Sample size is 56 adult males ( $P 1, C 2$, and C3 measurements only); 36 adult males form the sample for the remaining measurements. Certain measurements were omitted because of feather wear or damage so sample size used to calculate means of individual feathers is slightly less than total sample size. 


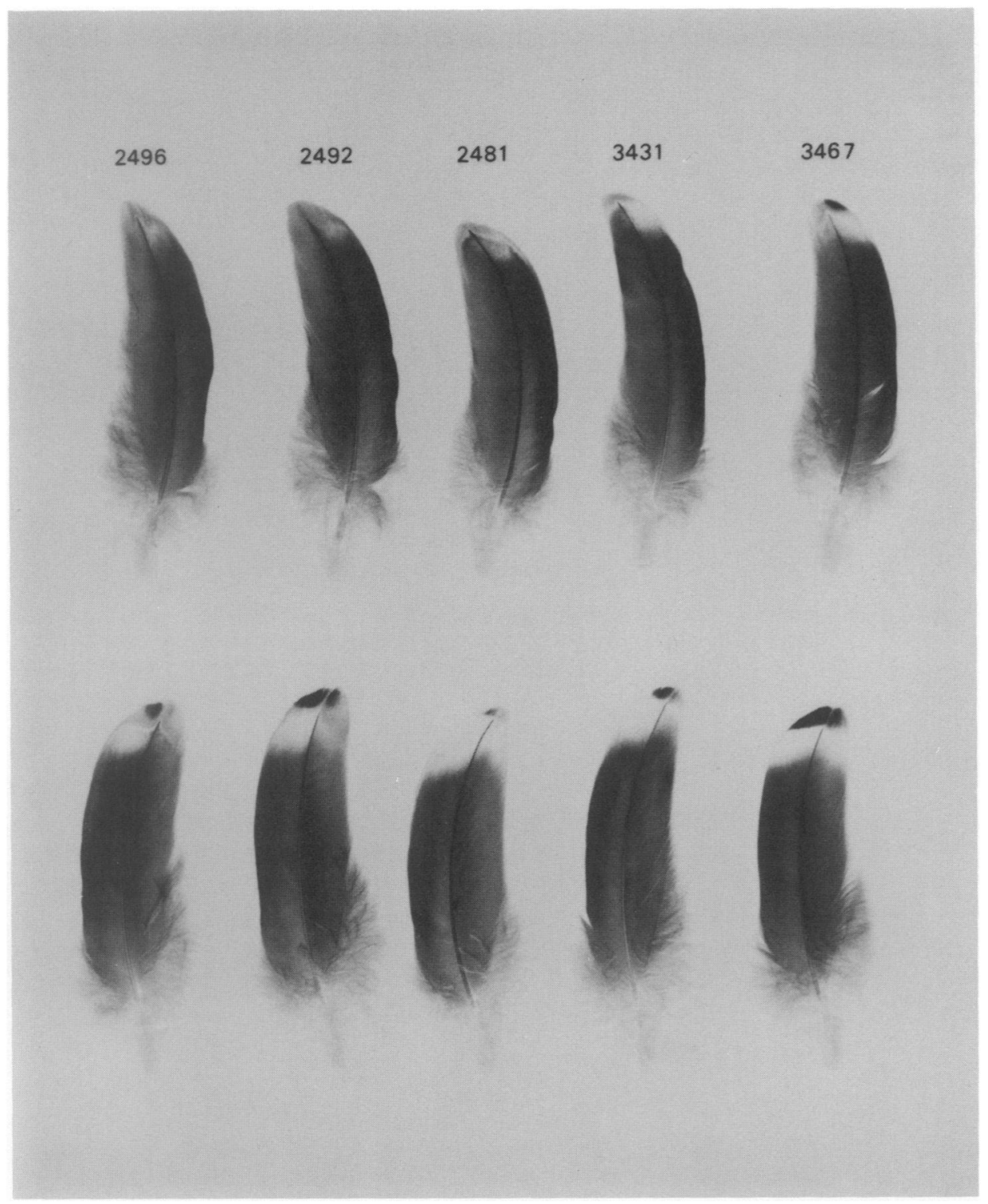

Fig. 2. Greater secondary covert 2 feathers from 5 females as yearlings (above) and as 2-year-olds (below). The blackwhite markings on feathers from yearling females are representative of the range of variation observed during the study.

ble 1 for aging, based on measurements taken in 1976, indicated that the combination of $\mathrm{P} 1, \mathrm{C} 2$, and $\mathrm{C} 3$ provided the most accurate age determinations. Among females, C2 was the best single feather for aging, and combined black-white surface area and weight were the best measurements. The highest level of accuracy was achieved with P1 diameter and weight, C2 black-white surface area, and 
maximum width and black-white surface area of C10. Among males, C3 was the best single feather for aging, and combined black-white surface area and weight were the best measurements. Using a combination of feathers, we obtained the highest level of accuracy for males with $\mathrm{P} 1$ diameter and weight and black-white surface area of C3. Feather diameter measurements were dropped from final discriminant functions, in part because analyses suggested that these data were more sensitive to handling procedures and because highly reliable alternative feather characters were available for aging.

The final DFs that were found to distinguish the age classes most reliably were based on measurements of weight and black-white area of selected feathers (Table 3). Thus, for example, if we applied $\mathrm{DF}_{1}$ to female mallard 2005 with measurements of $\mathrm{C} 2 \mathrm{~W}=36.10 \mathrm{mg}$ and $\mathrm{C} 2 B W=51 \mathrm{~mm}^{2}$, we would obtain:

$$
\begin{aligned}
\mathrm{DF}_{1} & =23.46-0.48(36.10)-0.21(51) \\
& =-4.58 .
\end{aligned}
$$

The negative sign would lead us to assign 2005 to the adult age class (which is correct). The variety of DFs (Table 3) en-

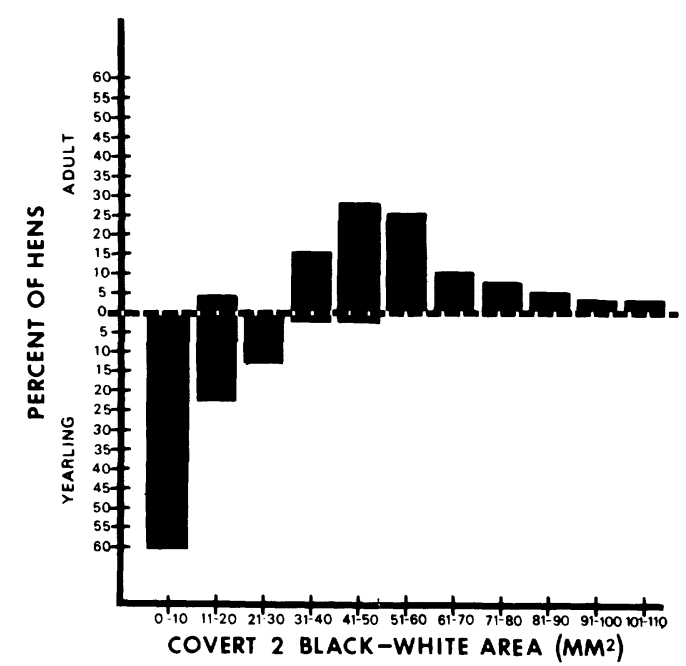

Fig. 3. Frequency distribution of yearling and 2-year-old hens in relation to size of black-white surface area of greater secondary covert 2 .

ables the investigator to select the one that matches the measurements he has available.

The performance of the different DFs can be judged by Table 3. Shown under the heading apparent error rates are the percentages of yearlings and adults in the data set that were erroneously classified by the DF. Also shown is the estimated actual error rate, described earlier,

\begin{tabular}{|c|c|c|c|c|}
\hline & \multirow[b]{2}{*}{ Discriminant function } & \multicolumn{3}{|c|}{ Error rate percentage } \\
\hline & & Apparent yearling & Apparent adult & Estimated \\
\hline \multicolumn{5}{|c|}{ Females } \\
\hline 1 & $23.46-0.48 \mathrm{C} 2 W-0.21 \mathrm{C} 2 \mathrm{BW}$ & 3.1 & 2.9 & 5.0 \\
\hline 2 & $32.44-0.26 \mathrm{C} 2 B W-0.15 \mathrm{P} 1 W$ & 3.2 & 2.5 & 3.4 \\
\hline 3 & $45.80-0.16 \mathrm{C} 2 B W-0.23 \mathrm{P} 5 L$ & 3.6 & 6.0 & 7.7 \\
\hline 4 & $8.61-0.15 C 2 B W-0.065 C 3 B W$ & 3.1 & 4.4 & 5.4 \\
\hline 5 & $53.20-0.12 \mathrm{C} 2 B W-0.062 \mathrm{C} 3 B W-0.26 \mathrm{P} 5 L$ & 3.6 & 4.5 & 6.5 \\
\hline \multicolumn{5}{|c|}{ Males } \\
\hline 1 & $21.40-0.21 \mathrm{C} 1 B W-0.10 \mathrm{P} 1 W$ & 0 & 8.6 & 10.4 \\
\hline 2 & $15.88-0.13 \mathrm{C} 2 B W-0.014 \mathrm{C} 3 B W-0.27 \mathrm{C} 2 W$ & 11.5 & 5.4 & 10.3 \\
\hline 3 & $22.51-0.14 \mathrm{C} 2 B W-0.096 \mathrm{P} 1 W$ & 3.8 & 8.9 & 9.0 \\
\hline 4 & $22.33-0.12 \mathrm{C} 2 B W-0.020 \mathrm{C} 3 B W-0.092 \mathrm{P} 1 W$ & 3.8 & 10.7 & 9.2 \\
\hline 5 & $8.13-0.088 \mathrm{C} 1 B W-0.048 \mathrm{C} 2 B W-0.092 \mathrm{C} 3 B W$ & 5.9 & 2.9 & 8.7 \\
\hline
\end{tabular}

Table 3. Discriminant functions and associated error rates for female and male mallards. 
which is a less biased assessment of the performance of the DF expected with future observations. The lowest estimated actual error rate was produced by $\mathrm{DF}_{2}$ based on measurements of $\mathrm{C} 2$ blackwhite area and P1 weight in females and by $\mathrm{DF}_{5}$ based on the measurements of $\mathrm{C} 1, \mathrm{C} 2$, and C3 black-white area in males.

\section{DISCUSSION}

Our data indicate that several combinations of feather measurements reliably separate yearling from adult females before and during the nesting season. The technique can also be used to separate yearling from adult males but at a higher error rate. The black-white surface area of $\mathrm{C} 2$ is the single most useful character identified during the study. It is fortuitous that the feathers providing the most reliable combinations of measurements for aging both males and females are distinguished easily, and their removal does not noticeably hinder flight.

Average sizes of feathers may vary among different populations, reflecting variation in overall body size. If the technique described here is to be employed on mallards that are suspected to differ appreciably in average size from those we used, we recommend that feather parameters be compared to averages in Table 2. We doubt that the DFs presented here are likely to be misleading when applied to mallards from most populations.

The quantitative procedures we used to develop an aging technique to assign individuals to either yearling or adult age classes have the advantage of removing subjective judgment as a significant factor. Whereas experience is a key factor in aging mallards by the qualitative methods of Hopper and Funk (1970), it is less important in the use of our technique.
The methodology of our technique precludes aging of birds in the field during capture operations. However, because magnitude of black and white can be visually estimated in the field, this characteristic is a potentially useful visual indicator of age that can be used in conjunction with existing keys of the types employed by Carney and Geis (1960) and Boyd et al. (1975). Boyd et al. did use greater secondary coverts for age determination. Their key describes juvenile female 4 th, 5 th, and 6 th greater secondary coverts ("greater coverts") as having a "small, rounded black tip," whereas those of adult females have a "large, angular black tip." Our data indicate that the magnitude of the black area at the tip of C2 is a particularly useful trait for separating yearlings from adults.

Although our findings should facilitate separation of yearling from adult mallards, particularly during the breeding period, there remains a need to explore potential avenues of research that might lead to development of a technique by which adults could be aged to specific year.

\section{LITERATURE CITED}

Anderson, B. W., AND R. L. Timken. 1971. Age and sex characteristics of common mergansers. J. Wildl. Manage. 35:388-393.

BarR, A. J., J. H. GoOdNight, J. P. SAll, AND J. T. HELWIG. 1976. A user's guide to SAS 76. SAS Institute Inc., Raleigh, N.C. 329pp.

Boyd, H., J. Harruson, aNd A. Allison. 1975. Duck wings: a study of duck production. A WAGBI Publication, Marley Ltd., and the Harrison Zoological Museum, Chester, Great Britain. $112 \mathrm{pp}$.

CARNeY, S. M. 1964. Preliminary keys to waterfowl age and sex identification by means of wing plumage. U.S. Fish Wildl. Serv. Spec. Sci. Rep. Wildl. 82. 47pp.

_ AND A. D. Geis. 1960. Mallard age and sex determination from wings. J. Wildl. Manage. 24:372-381.

Chan, L. S., AND O. J. DunN. 1972. The treatment 
of missing values in discriminant analysis-I. The sampling experiment. J. Am. Stat. Assoc. 67:473-477.

DANE, C. W. 1968. Age determination of bluewinged teal. J. Wildl. Manage. 32:267-274. , AND D. H. JoHNSON. 1975. Age determination of female redhead ducks. J. Wildl. Manage. 39:256-263.

GreenberG, R. E., S. L. EtTer, AND W. L. ANDERSON. 1972. Evaluation of proximal primary feather criteria for aging wild pheasants. J. Wildl. Manage. 36:700-705.

Hopper, R. M., AND H. D. FuNK. 1970. Reliability of the mallard wing age-determination tech- nique for field use. J. Wildl. Manage. 34:333339.

LACHENBRUCH, P. A. 1975. Discriminant analysis. Hafner Press, New York. 128pp.

- AND M. R. MICKEY. 1968. Estimation of error rates in discriminant analysis. Technometrics 10:1-11.

OrING, L. W. 1968. Growth, molts, and plumages of the gadwall. Auk 85:355-380.

SMART, M. G. 1962. Biological problems in the restocking of redhead ducks (Aythya americana). M.A. Thesis. Univ. of Missouri, Columbia. $115 p$.

Received 2 December 1977.

Accepted 8 October 1978. 